\title{
Lazer nos rios urbanos da Tríplice Fronteira: transformações, contradições e significados
}

\author{
Leisure at urban rivers of Three-Border Region: transformations, con- \\ tradictions and meanings
}

\section{Ocio en los ríos urbanos de la Triple Frontera: transformaciones, con- tradicciones y significados}

\section{Sandra Akemi Narita ${ }^{1}$ Christianne Luce Gomes ${ }^{2}$}

Resumo: A discussão sobre os rios urbanos, na sua interface com o lazer, foi o tema desta pesquisa, com foco na cidade brasileira de Foz do Iguaçu - localizada na Tríplice Fronteira que reúne, ainda, Puerto Iguazú (Argentina) e Ciudad del Este (Paraguai). O objetivo geral foi identificar e discutir as apropriações sociais e vivências de lazer realizadas nos rios urbanos Paraná e Iguaçu, e suas margens. Procurou-se entender suas transformações e contradições e, ainda, de que maneira os moradores significam esses ambientes fluviais. A metodologia desta pesquisa qualitativa contou com estudo bibliográfico, observações e entrevistas com 23 moradores de Foz do Iguaçu. Nesse trabalho, verificou-se que as apropriações e vivências de lazer tornaram-se pontuais à medida que as mudanças urbanísticas e no meio natural praticamente desprezaram um sentido integrativo entre a cidade e o ambiente fluvial. Restam, no entanto, nos rios e nas suas margens, práticas como pesca por lazer e esportes de aventura, que imprimem múltiplos significados, por meio de vivências lúdicas, contemplativas, espirituais e interativas com as águas. Houve, no município, uma opção pelo olhar privilegiado voltado ao turista, fato que impacta diretamente nos espaços públicos e democráticos de lazer, para os moradores, como os localizados nos rios e suas margens.

Palavras-Chave: Lazer. Cidade. Meio ambiente. Turismo. Tríplice Fronteira

Abstract: The discussion about urban rivers, in its interface with leisure, was the theme of this research, focusing on the Brazilian city Foz do Iguaçu, located in the Three-Border Region along with Puerto Iguazú (Argentina) and Ciudad del Este (Paraguay). The general purpose of this research was to identify and discuss the social appropriations and leisure experiences that happen in urban rivers Paraná and Iguaçu and margins. The present study also aimed at understanding their transformations and the contradictions, and also how locals signify these fluvial environments. The methodology of this qualitative research included a bibliographic study, observations and interviews with 23 inhabitants of Foz do Iguaçu. Through this study, it is possible to see that the appropriations and leisure experiences have become punctual as urban and environmental changes ignored an integrative sense between the city and its fluvial environments. There is still, in the rivers and their margins, activities such as leisure fishing and adventure sports being done, that attribute different meanings to these rivers through ludic, contemplative, spiritual and interactive experience with the waters. A privileged

1 Universidade Federal da Integração Latino-Americana (UNILA). Belo Horizonte, MG, Brasil

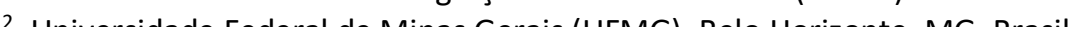


look focused on tourists has been prioritized and this has had an impact on public and democratic leisure areas for dwellers, such as rivers areas and their margins.

Keywords: Leisure. City. Environment. Tourism. Three-Border Region.

Resumen: La discusión sobre los ríos urbanos, en su interfaz con el ocio, fue el tema de la investigación, con foco en la ciudad brasileña Foz do Iguaçu, ubicada en la Triple Frontera, que reúne, aún, Puerto Iguazú (Argentina) y Ciudad del Este (Paraguay). El objetivo general en esta investigación fue identificar y discutir las apropiaciones sociales y las vivencias del ocio en los ríos urbanos de Foz do Iguaçu y sus orillas. La investigación también buscó sus transformaciones y contradicciones, aún cómo los residentes significan los ríos y sus orillas. La metodología en esta investigación cualitativa involucró un estudio bibliográfico, observaciones y entrevistas con 23 residentes de Foz do Iguaçu. Esta investigación verificó que las apropiaciones y las vivencias de ocio son puntuales, dado que los cambios urbanos en el medio natural prácticamente no dieron cuenta del sentido de integración entre la ciudad y el medio fluvial. Todavía hay en el ambiente fluvial y en sus orillas prácticas como pesca para el ocio y deportes de aventura, los cuales imprimen distintos significados por medio de vivencias lúdicas, de contemplación, espirituales e interactivas con las aguas. Hubo, en la municipalidad, una opción por la mirada puesta al turista, lo que impacta directamente en los espacios públicos y democráticos de ocio para los moradores, como los ubicados en los ríos y sus orillas.

Palabras clave: Ocio. Ciudad. Medio ambiente. Turismo. Triple Frontera.

\section{INTRODUÇÃO}

A imagem de Foz do Iguaçu como a "Terra das Cataratas", ou o "Destino do Mundo 3 ", aparece em slogans propagados no Brasil e no exterior com finalidades turísticas. São marcas que foram tatuadas ao longo da história dessa cidade, localizada no extremo oeste do estado do Paraná, e integrada à chamada Tríplice Fronteira. Essa área fronteiriça abrange, ainda, Ciudad del Este, no Paraguai, e Puerto Iguazú, na Argentina. As fronteiras entre Foz do Iguaçu e essas duas cidades são naturais, estabelecidas pelos rios Paraná e Iguaçu, respectivamente.

É às margens do rio Paraná que o adensamento populacional da cidade é maior, se comparado ao rio Iguaçu. Apelidado de "Paranazão", o rio Paraná desfila $4.800 \mathrm{~km}$ e é o principal formador da Bacia do Prata, uma das mais importantes bacias transfronteiriças da América do Sul. O rio Iguaçu, por sua vez, tem uma associação direta sobretudo com o turismo, devido às cataratas do Iguaçu, localizadas no Parque Nacional do Iguaçu, que funciona por meio de parcerias público-privadas. Fica claro, portanto, a centralidade fluvial na região da Tríplice Fronteira, cujas cidades são conectadas por ambientes fluviais e que, segundo Oliveira (2012, p.37),

\footnotetext{
${ }^{3}$ Foz do Iguaçu, como "Destino do Mundo", partiu de uma campanha que destaca a cidade das Maravilhas, Emoção, Conforto, Sabores, Eventos e Compras, com objetivo mudar a imagem do Destino Iguaçu, transformando-o, cada vez mais, em um destino turístico de qualidade para lazer, eventos, ecoaventura e compras. A campanha nasce em 2007, a partir de uma Gestão Integrada do Turismo, formada por Itaipu, Prefeitura Municipal de Foz do Iguaçu, Conselho Municipal de Turismo, Instituto de Promoção Turística do Iguassu (Convention Bureau), Sindihotéis, ICMBio, Instituto Polo Iguassu, para "divulgar, promover, qualificar, melhorar a infraestrutura e fortalecer a imagem do Destino Iguaçu. (...) A partir de então, todas as ações passaram a ser integradas e demais entidades representativas do trade turístico." (Fonte:

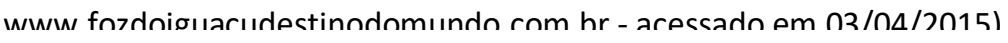


[...] corresponde a sistemas inter e transnacionais permeáveis, cuja plasticidade social se faz nas relações entre pessoas e culturas em constantes e descontínuas deslocações no interior e no cruzamento de três estados nacionais demarcados por fronteiras voláteis, difusas e intrigantes, literalmente líquidas e fluidas...

A autora supra mencionada chama a atenção, nesse trecho, para as singularidades e complexidades que gravitam em torno de um município que é conhecido por abrigar gente vinda de diversos cantos do Brasil, e por ser local de fluxo de passagem de brasileiros, argentinos, paraguaios, chineses, árabes, dentre outras nacionalidades. Um cenário que, portanto, gera uma diversidade de relações e identidades entre o morador e a cidade de Foz do Iguaçu.

Na Tríplice Fronteira, por trás de sua caracterização como uma unidade urbana singular está, principalmente, o movimento da Ponte da Amizade - e as atividades que esse espaço supõe, marcadas pelo comércio e, muitas vezes, como aponta Rabosssi (2011), por atividades ilícitas. Essa ponte é o elo terrestre entre Foz do Iguaçu e Ciudad del Este e foi construída sobre o rio Paraná.

Considerando esse ambiente trinacional de significativa receptividade turística, indaga-se: quais relações os moradores de Foz do Iguaçu estabelecem cotidianamente com os rios, e quais práticas de lazer são desenvolvidas nesse contexto? Essa foi a pergunta central que guiou esta pesquisa. Para respondê-la, definiu-se como objetivos específicos identificar e discutir as transformações e contradições que ocorrem nos rios urbanos de Foz do Iguaçu, impactando as vivências de lazer dos moradores da cidade. $E$, ainda, buscou-se compreender de que maneira esses sujeitos significam os espaços fluviais, que marcam a identidade desse município paranaense. $O$ alcance desses objetivos foi possibilitado pelas estratégias metodológicas que serão especificadas a seguir.

\section{METODOLOGIA}

Esta pesquisa teve um caráter qualitativo e descritivo à medida que buscou apreender as práticas e experiências, os contextos e as apropriações de sujeitos nos rios. Além de estudo bibliográfico e observações, a pesquisa realizou entrevistas com 23 moradores de Foz do Iguaçu, de idades entre 18 e 73 anos, sendo 16 homens e 7 mulheres. Esses depoentes tiveram o anonimato preservado por meio de nome fictício, criado com base nas profissões, origens, características tais como faixa etária e atividades realizadas no rio. A pesquisa bibliográfica percorreu estudos que pudessem contribuir na análise de temáticas da pesquisa, como lazer, apropriações de espaços públicos, urbanização, meio ambiente e rios. Essa pesquisa debruçou-se, também, sobre o contexto de Foz do Iguaçu e suas águas, tendo em vista apreender as trajetórias de mudanças na estrutura urbana, temas centrais para compreender o lazer nos rios urbanos da cidade.

Para as entrevistas, inicialmente, identificou-se moradores da cidade que tivessem vínculo próximo com o rio, e tivessem papel de liderança, seja por engajamentos, por práticas de lazer diversas, ou, ainda, por trabalhos desenvolvidos em ONG's ligadas ao rio e na área de educação ambiental. Também buscou-se, nesse princípio, moradores que fossem conhecedores dos meandros dos ambientes fluviais. Outros critérios previamente estabelecidos na escolha foram serem adultos e moradores de Foz do Iguaçu. Nesse momento, 10 pessoas com esse perfil foram entrevistadas.

Nos rios urbanos de Foz do Iguaçu, dois espaços foram escolhidos para realizar a observação 
e também outras entrevistas: o Marco das Três Fronteiras, onde seis pessoas foram entrevistadas; e na chamada "Prainha", formada a partir do lago de Itaipu, onde foram colhidos mais sete depoimentos, totalizando 23 entrevistas. Os critérios utilizados para a escolha desses pontos de observação partem do fato de serem espaços do rio Paraná localizados em perímetro urbano de Foz do Iguaçu, e de livre acesso à população, de forma gratuita. Esses locais estão distribuídos em duas regiões periféricas da cidade: sul e norte, respectivamente. A localização em espaços urbanos justifica-se na medida em que a pesquisa busca compreender possíveis relações entre os rios e a cidade/população urbana de Foz do Iguaçu.

A definição desses locais foi subsidiada, sobretudo, pelas primeiras entrevistas. Outro critério para a escolha desses pontos de observação foi a identificação de algumas potencialidades para práticas de lazer, seja por meio de algum tipo de acesso - físico ou visual -, ou ainda práticas interativas no rio ou às suas margens. As visitas foram feitas nos finais de semana, durante um verão ensolarado iguaçuense, no período compreendido entre novembro de 2014 e fevereiro de 2015.

A análise das informações foi realizada com base em interpretações das entrevistas e leituras bibliográficas, a partir da codificação que, para Gibbs (2009), é "uma forma de indexar ou categorizar o texto para estabelecer uma estrutura de ideias temáticas em relação a ele" (p.60). Bodgan \& Biklen (1994) atentam para os passos da análise por meio de codificação, que percorrem à procura de regularidades e padrões, tópicos presentes nos dados e, em seguida, escrita de palavras e frases categorias de codificação -, que representam estes mesmos tópicos e padrões. A escolha de categorias de análise foi feita com base principalmente nas perguntas e nos objetivos da pesquisa.

\section{O RIO PARANÁ: TRANSFORMAÇÕES E CONTRADIÇÕES}

O crescimento urbano de Foz do Iguaçu abriu um abismo de separação entre os moradores e o ambiente fluvial da cidade, a partir de um tensionamento entre os ambientes natural e construído. Essas tensões aprofundam-se sobretudo pelos processos de ocupações, acompanhadas pelos conflitos de moradia, sobretudo às margens dos rios. Thaumaturgo (2012) identificou que, em 1960, os pequenos núcleos urbanos da cidade estavam distribuídos na pequena faixa de 1,82km². Em 1995, a malha urbana de Foz do Iguaçu alcança $130 \mathrm{~km}^{2}$ e, em 2007, chega a $191 \mathrm{~km}^{2}$. Dados do IBGE ${ }^{4}$ apontam que, em 2010, a cidade contou com uma população de 256.088 pessoas (sendo 99,2\% residentes em área urbana), e densidade demográfica de $414,58 \mathrm{hab} / \mathrm{km}^{2}$.

Nesse contexto, estão espaços onde a disputa nas relações de forças apresenta-se tensionada, sobretudo por processos de lutas que empurraram a população mais pobre para moradias precarizadas e improvisadas nas margens fluviais, especialmente do rio Paraná. Esse braço fluvial ainda mostra sua imponência, tal qual a Ponte Internacional da Amizade, construída sobre ele em 1965, para ser o enlace terrestre entre Ciudad del Este e Foz do Iguaçu. No contexto urbano, o rio Paraná e seus afluentes fluem em um universo tensionado na relação sociedade-natureza. Uma marca indelével nesse rio foi a construção da hidrelétrica de Itaipu, que provocou o desaparecimento do cenário natural das Sete Quedas ${ }^{5}$, no município paranaense de Guaíra.

\footnotetext{
${ }^{4}$ Fonte: IBGE <http://cidades.ibge.gov.br>. Acessado em 02/07/2014.

${ }^{5}$ Sete Quedas é formada por um conjunto dezenove cachoeiras e noventa saltos, em um desnível de 100 metros. O desaparecimento dessa paisagem não teve um tom pacífico e foi marcado por movimentos como o "Adeus Sete Quedas", que reuniria músicos, escritores e outros artistas, além de pessoas ligadas ao movimento erolńoirn rentra ecce decactre natıral raıcandn dannc amhientaic irrevercíveic
} 
Por conta da hidrelétrica, foi preciso mudar a estrutura natural do rio Paraná e construir um reservatório que ocupou $1350 \mathrm{~km}^{2}$, submergindo uma área total de $780 \mathrm{~km}^{2}$, do lado brasileiro, e $570 \mathrm{~km}^{2}$ no Paraguai. Como consequência direta, no solo do Brasil, oito municípios do Oeste do Paraná ${ }^{\text {foram }}$ atingidos, entre eles Foz do Iguaçu. A porção submersa nessa cidade representou 49.538 ha, onde havia população de 5.609 pessoas. O espaço total comprometido com a represa de Itaipu, formação do lago e reflorestamento marginal abrangia uma área onde a população estimada era de 42.444 pessoas, sendo 38.445 habitantes da zona rural e $49,93 \%$ de pessoas ocupadas, ou seja, que exerciam algum tipo de trabalho (Germani, 2003). Contingente que, grande parte, foi expulso de forma compulsória de suas terras, no período de 1978 a 1982.

Segundo Catta (2009), no período de construção da hidrelétrica, houve um aumento exorbitante da população em Foz do Iguaçu que, em 1970 possuía 33.970 habitantes e, em 1980, com as obras pleno andamento, saltou para 136.320 moradores, dos quais a maioria era de residentes na área urbana. A construção de Itaipu na década de 1970, bem como o crescimento do comércio - com forte influência da criação de uma zona franca em Ciudad del Este - são destacados como os principais marcos, ou ciclos da cidade, pela história de cunho mais oficial e memorialista, de Foz do Iguaçu. Partem dessa visão, também, os marcos da ascendência do turismo, decorrente principalmente das visitas às Cataratas do Iguaçu. E, ainda, o ciclo dos anos 80 e início dos anos 90 , no qual o turismo de compras na cidade paraguaia alcança seu apogeu - sobretudo pelo fenômeno marcado pela intensificação da atividade dos chamados "sacoleiros", que transportavam, por meio da Ponte da Amizade, mercadoria de Ciudad del Este para revenda no Brasil.

González (2005) reconhece a importância de estudos que demarcam a história da cidade a partir desses ciclos em Foz do Iguaçu. No entanto, segundo o autor, essa perspectiva contribui para invisibilizar outros campos de memória sobre a cidade, de outros sujeitos sociais, em uma perspectiva de luta pela cidade, travada no âmbito da cultura - da representação, por valores e direito de construção deles. $O$ autor enfatiza que a expansão da malha urbana na cidade não pode ser tomada como obra exclusiva do capital, mas também como resultado de luta entre grupos sociais distintos, a partir de seus parâmetros de uso do solo urbano.

Pressões das populações marginalizadas criaram um movimento, desde a década de 1970, que forçaram recuos de projetos urbanos de forças políticas e empresariais, além de respostas do poder público sobre a questão das moradias - especialmente nas áreas centrais. Ou seja, "movimentos de ocupação urbana foram, em certo sentido, o próprio motor do desenvolvimento urbano da cidade, e não 'reflexo' dele". (González, 2005, p. 61)

Sobretudo nos anos de 1980, muitos dos planejamentos urbanos e projetos realizados pelo poder público e empresarial podem ser interpretados como respostas a movimentos de ocupações urbanas. As reivindicações desses grupos foram importantes para a construção e a definição dos novos espaços sociais de uso, de mobilização política e de sobrevivência da população de Foz do Iguaçu. Nesse crescimento populacional, além de necessidades como moradia e saneamento, o lazer entra como mais uma demanda, nascida dessa nova estrutura urbana que deveria atender aos direitos dos que ali moram. Hoje, o principal ponto de lazer destacado na cidade - ao menos para o olhar estrangeiro - é o Parque Nacional do Iguaçu, um tema que será discutido no tópico a seguir.

\footnotetext{
${ }^{6}$ Além de Foz do Iguaçu, outros municípios atingidos pela construção de represa de Itaipu foram Guaíra, Terra Rnxa Marerhal Cândidn Rondon Santa Helena Matelândia Medianoira e Sãn Mioı
} 


\title{
4.1 "Terra das Cataratas" - E os Moradores?
}

A pesquisa bibliográfica e a busca de informações em sites oficiais para contextualizar o objeto investigado revelou que as "marcas" em Foz do Iguaçu de uma cidade voltada para o turismo, principalmente a partir do braço fluvial do rio Iguaçu, estão estampadas nas propagandas de divulgação nacional e internacional. Essa "função" da cidade traz reflexos no cotidiano dos moradores, ganhando entendimento mais profundo quando se insere em uma rede complexa de atores e estrutura social, política, econômica e cultural da cidade.

Foz do Iguaçu, de fato, tem um preparo para o turismo: em 2011, são contabilizados, no total, 133 meios de hospedagem - entre hotéis, e pousadas -, número que não inclui a quantidade crescente de albergues, ou os chamados hostels. ${ }^{7}$ A tão propalada vocação turística, colocada como se fosse determinada por uma "condição natural", possui uma trajetória de construção discursiva por parte da classe dominante de Foz do Iguaçu. Nesse sentido, as águas da cidade, em especial as que correm pelo rio Iguaçu, foram objeto de construção de um imaginário da cidade, voltado para um "olhar estrangeiro". Assim, reduzir o passado da cidade à vocação turística, segundo Souza (2009, pp. 10-11) "foi estratégia importante de legitimação dos interesses dos defensores dessa proposição: o domínio sobre o passado, ou melhor, sobre seu significado no presente".

O rio, com suas belezas e energias, imprime o tom do cartão postal da cidade, que cumpre a função de mostrar suas riquezas a um olhar de fora. E a perspectiva dos moradores? Quais as suas percepções, ações e histórias que também estão impressas e marcam a cidade de Foz do Iguaçu? Souza (2009), em sua pesquisa, trabalhou com vozes "silenciadas" de trabalhadores da cidade - e sua visão sobre o turismo, que levanta contradições e um ambiente de tensões em Foz do Iguaçu. A pesquisadora faz o relato, fruto desse trabalho:

\begin{abstract}
Qualquer cidade considerada "turística" ou "balneária" sustenta-se no trabalho de um exército de pessoas, que a fazem funcionar como cidade do "lazer". Assim, o "lazer", o "ócio", o "descanso", e o "divertimento" são estruturados como um negócio. Foi assim que o turismo apareceu, na fala dos trabalhadores. O turismo, como desfrute, era uma atividade para os outros. Hotéis, restaurantes, rodoviárias, avenidas, praças, táxi, aeroporto, hospitais, meios de comunicação, tudo, na cidade, está organizado, em função de garantir um padrão adequado de atendimento do turista. A cidade por onde o turista passa deve ser bem sinalizada, pavimentada, limpa, arborizada, acessível (Souza, 2009, pp. 193-194).
\end{abstract}

Conflitos que envolvem a apropriação e a produção cotidiana da cidade suscitam questionamentos sobre o planejamento da estrutura urbana de Foz do Iguaçu, pois, o convívio entre as pessoas em espaços democráticos para os moradores não foi priorizado no conjunto das transformações já destacadas. Nesse sentido, vale pontuar que não parece

\footnotetext{
7 Dados da Secretaria Municipal de Turismo, obtidos no relatório “Dados Econômicos de Foz do Iguaçu 2011". (Fonte: Prefeitura Municipal de Foz do Iguaçu, em http://www.pmfi.pr.gov.br/ArquivosDB?idMidia=62501 - arescadn em $\mathrm{n} / \mathrm{n} \Delta / 215)$
} 
haver uma intencionalidade "rancorosa" sobre o turismo; há, sim, questionamentos sobre o direcionamento de núcleos de investimentos, silenciamentos e "cegueiras" para determinadas áreas e camadas da população. Nesse bojo, está uma lacuna de espaços públicos e democráticos de lazer para os moradores da cidade que, embora privilegiada por ambientes naturais, suas paisagens não estão integradas com a população. Uma contradição, portanto, presente no olhar de "costas" para uma abundância dos ambientes fluviais, que ganham relevo na cidade, sobretudo por conta do turismo no Parque Nacional do Iguaçu.

Nesse mosaico imbuído de complexidades, contradições e embates sociais atua, portanto, uma rede de forças, que trazem impactos na construção do município e aos moradores. Inclusive sobre seus espaços públicos, negligenciados sobretudo por um olhar da cidade como mercadoria turística. O entendimento de espaço público, colocada por Vainer (2000), é do lugar do discurso político e debate. Esse diálogo acontece por meio do domínio da interlocução, para que aconteça processos de comunicabilidade. Hoje, o desafio para essa comunicação é "retomar o espaço público como lugar de uma participação ativa, normatizada e refundá-la como um espaço da política." (P. Gomes, 2012, p. 161.) O espaço público, nesse sentido, como aponta P. Gomes (2012), não pode prescindir da dimensão física que, na cidade, inscrevem-se potenciais para o encontro com o outro, a co-habitação, o diálogo e a comunicação, o debate, e as sociabilidades.

A origem das cidades, da ideia da polis, surge, segundo Rolnik (2000), do princípio da igualdade e da diferença, fundado na possibilidade de pessoas conviverem com o diferente e o diverso; uma convivência conjunta a partir de um contrato político entre elas. $A$ discussão espacial, portanto, tem sua importância na compreensão das imbricações entre rio-cidade-lazer democrático, na medida em que esse debate contribui para pensar questões no universo das relações sociais, de poder, de identidade e das apropriações materiais e simbólicas. Essa citada tríade, em Foz do Iguaçu é o tema que segue a discussão.

\subsection{Lazer nos Rios Urbanos}

Nesta pesquisa, o lazer é entendido como

[...] a necessidade de fruir, ludicamente, as incontáveis práticas sociais constituídas culturalmente. Essa necessidade concretiza-se na ludicidade e pode ser satisfeita de múltiplas formas, segundo os valores e interesses dos sujeitos, grupos e instituições em cada contexto histórico, social e cultural. Por isso, o lazer precisa ser tratado como um fenômeno social, político, cultural e historicamente situado. (Gomes, 2014, p.12).

Nesse sentido, a tríade rio-cidade-lazer, em Foz do Iguaçu, possuía uma marca que passa pela formação da identidade histórica da população, cujas águas próximas às suas residências eram abraçadas com um sentimento de pertencimento e apropriação, como pode ser percebido nesses depoimentos:

"Começo do anos 70, esse pessoal desta época de quando meu pai chegou, logo 
quando eu nasci, curtia muito o rio. Então o pessoal que é de Foz, nascido aqui, tem essa herança que já vem de nossos pais, de que eles tinham relação muito próxima com o rio, mesmo os que não moravam tão próximos ao rio. O principal lazer daquela época sempre foi o rio" ("Aventureiro").

"Aqui em Foz do Iguaçu e região, a gente é conhecido como homem do rio, porque quando os colonizadores chegaram, o barraco, a casa, sempre acampavam à margem de um rio ou um córrego, então o rio passou a ser muito importante pela água que pela dificuldade. Tomava banho era no rio, lavar roupa era em um rio. (...) Lamentável hoje nossos rios e córregos tão contaminados, poluídos aqui. Cresceu a cidade e esse é o preço do progresso" ("Guarani").

Um espaço em Foz do Iguaçu que perdeu suas características por conta do "progresso", ou meIhor, vem desaparecendo ao longo do tempo, são os chamados "areiões", ou "praias" beira-rio, locais onde eram abrigadas atividades de lazer. Hoje, esses espaços naturais foram praticamente apagados da paisagem de Foz do Iguaçu, por conta da atividade comercial de extração de areia - ainda presente - e, também, das modificações na estrutura dos rios.

\begin{abstract}
"Antigamente as pessoas iam pro rio pro lazer. A gente ia, sentava, tinha areia da praia. Você sentava na areia, as crianças na água. Era pai pensando que tava pescando, coisas de crianças - gritando na água - e mães cuidando, e às vezes havia fogãozinho, levava lanche, bebida. (...) Temos mesmo problema aqui que o (rio) São Francisco. Se você notar, prainhas que somem. Quando faz represa, segura areia. A cor do Paraná hoje você vê que ele é azulado, isso porque não tá vindo areia e não vai fazer praia. (...) Se você estiver em cima da barreira, olha pra baixo, quando ela (a água) sobe e cai, ela ainda tá escura, quando pára a confusão toda, fica azulada; isso é falta de areia. Eu protesto contra esta perda de praia" ("Canoista").
\end{abstract}

O protesto do "Canoísta" é pela perda de um dos principais espaços públicos para o lazer de Foz do Iguaçu. Outro ponto de contato com o rio, cujo elo foi perdendo-se ao longo do tempo são os portos, que foram fechados ou privatizados. A opção viária para conectar as cidades da Tríplice Fronteira foi clara, pelo menos no lado brasileiro. O antigo Porto Oficial encerrou suas atividades no mesmo período da inauguração da Ponte da Amizade, nos anos 1960 . Hoje alguns barcos de turismo e navegações comerciais circulam pelo ambiente fluvial. O trânsito de moradores da cidade brasileira pelos rios, portanto, foi diminuindo com o tempo, assim como o elo de ligação fluvial, como relatam depoentes.

"O uso do rio era bem mais antes, porque o acesso, as ruas eram os rios. E agora abriu caminho por todo lado, ruas por todo lado, então o pessoal dificultou mais o barco e começou a frequentar mais por terra os locais. (...)Tinha barco de poupa de motor, você pagava, claro. E tinha barco a remo, que não tinha muita pressa, pagava baratinho, mas levava também, você chegava no destino. Tudo, da Argentina pro Paraguai, do Paraguai pra Argentina, da Argentina pro Brasil e do Paraguai pro Brasil e vice-versa" ("Guarani").

Na relação com Ciudad del Este e Foz do Iguaçu, a existência de diversos portos ilegais transformam alguns espaços da beira-rio dessas duas cidades em territórios mediados pela sobrevivência e por atividades ilícitas. Estas são forças que, ao prevalecerem, foram apontadas pelos moradores entrevistados como principais responsáveis pelo afastamento de práticas de lazer nos rios fronteiriços.

"O tráfico é antigo, veio em escalas. Primeiro o tráfico de erva-mate e madeiras, 
era do chamado ouro verde. Não tinha tanto risco você frequentar o rio. Começou a ficar perigoso quando começou o tráfico da farinha de trigo, início da década de 70, da Argentina para o Brasil, a era do ouro branco. Aí começou o tráfico com tiroteio, a Polícia Federal contra contrabandista. Depois começou o tráfico de drogas e armas, e aí começou a ficar perigoso. Começou em grande escala, no início dos anos 80. Aí veio o tráfico das muambas do Paraguai. Foi o que mais derrubou o lazer dos rios. As pessoas vão ainda, mas vou ou não vou, vou e será que vou voltar..." ("Guarani").

A cidade, enquanto ambiente construído, produzido para a reprodução ou sobrevivência, requalifica problemas elementares e introduz novas e complexas questões, a exemplo da violência urbana, que deve ser entendido dentro desse contexto interconectado, e não como um caso isolado ou individual.

A interação lúdica com o rio, por meio do lazer, foi perdendo espaço com a clara contradição de abundância e potencialidades do rio que, no entanto, foram sendo inviabilizadas, a partir da posição de "costas" para esse ambiente fluvial. Outra contradição está no potencial do rio e margens para espaços públicos de lazer, com investimentos sobretudo privados, gerando nichos de usuários dos rios, a exemplo de clubes ao longo do rio Paraná. Nesse sentido, o que está sendo posto não é simplesmente a dicotomia público x privado, tampouco a condenação desses empreendimentos privados. E sim, em certa medida, uma contradição e, seguramente, uma discrepância que existe entre o que foi apropriado pelo poder privado em espaços públicos, e o descaso público sobre o que poderia potencialmente ser espaços apropriados democraticamente pela população de Foz do Iguaçu, para o lazer. O acesso a esses espaços é uma das problemáticas apontadas pelos depoentes. Os chamados areiões, citados no início deste capítulo, eram um dos acessos facilitados, ou locais onde possibilitava-se chegar aos rios.

"A questão é que fomos criando outros tipos de hábitos. Hoje aqui existem muitos balneários, a prainha. Daí você prefere pegar tua família [...] porque no rio você descer não oferece conforto, é cheio de pedra, tem que descer pirambeira, não é que nem você pegar ... e vai adquirindo outros hábitos, né? Com a família, você não dá pra ir, só se for molecada, mas esposa, levar os filhos, as meninas, já fica difícil. Minhas filhas vão no domingo nadar, desce pra nadar no Paranazão, mas antigamente era mais... enchia sabe, via muita gente, as pessoas assando carne na beira do rio. Tinha areia, mas o pessoal vai tirando toda areia..." ("Brasiguaio").

\begin{abstract}
"Tem vários aspectos que dificultam que a população usufrua do rio. Boa parte está no Parque Nacional e o Parque Nacional não permite que você se banhe, ou o faça pra transportes, não pesque. Não pode, né?! Outra parte do rio pega algumas áreas rurais, que são propriedades particulares. Então só vai entrar quem conhece esses moradores. E depois a outra parte que margeia a fronteira oferece os riscos de uma fronteira, onde não tem uma vigilância adequada, que tem contrabando, que afeta também. Acho que é por isso que reduz as possibilidades. O pessoal vai mais pro lago (Itaipu) mesmo... pros clubes, pelo late Clube, pro (clube) Maringá, o pessoal mais elitizado que tem lancha" ("Escaladora").
\end{abstract}

Em Foz do Iguaçu, o modelo de cidade que valoriza os encontros da diversidade e do diferente, nos espaços públicos, não é potencializado. Possui ainda o agravante de, como enfatizado em momentos anteriores, buscar organizar a cidade voltada para a visão de local para "turista ver". Essas questões contraditórias, construídas historicamente, certamente não coloca como prioridade as apropriações sociais do morador da cidade. 


\begin{abstract}
"Primeiro você tem que construir pro morador. A partir do momento que você tem espaço pro morador, o turista vai usufruir também, acho que esse é o caminho certo. Isso que talvez falte um pouco. O turismo é a principal indústria da cidade, então nesses fóruns acaba ficando muito... falam muito o acesso pro turista, a via pro turista, há esse erro de interpretação, deveria ser o contrário. Constrói um ambiente pra que o morador tenha uma boa qualidade de vida, aí o turista vai usufruir disso tudo que existe pro morador. Aí o turista acaba se envolvendo com a cidade, acaba gastando mais. A gente vê muito o turista jovem, o turista estrangeiro, o mochileiro, esse novo perfil de turista que tá vindo pra cidade. Eles perguntam: mas o que as pessoas da cidade fazem?" ("Aventureiro").
\end{abstract}

Nesse conjunto de contradições que surgiram ao longo das entrevistas e pesquisa, é relevante pontuar que alguns depoentes colocam justamente Itaipu Binacional como o principal ator que está pensando o "desenvolvimento sustentável" na cidade, embora nem todos os entrevistados seguissem essa linha de pensamento.

\begin{abstract}
"Se você me perguntar hoje quem pensa em meio ambiente no município de maneira consciente, apesar se a gente analisar profundamente, é Itaipu. Ela causou uma grande intervenção no meio ambiente, mas pelo menos eles pensam no meio ambiente, eles pensam no desenvolvimento sustentável. Atualmente o município ganhou a concessão de ser o tutor ou o responsável pelas licenças ambientais. Nós estamos observando é um descaso, é como se fosse dar a caneta na mão de louco, porque a gente não tá vendo critério nenhum. Não existe um pensamento de desenvolvimento ambiental, existe um pensamento de desenvolvimento econômico" ("Esportista").
\end{abstract}

Sobre os impactos de Itaipu Binacional, seguimos a abordagem de um espaço imbuído da contradição de ser um dos principais locais de lazer, que nasce a partir do represamento do rio Paraná: a Prainha de Três Lagoas. O rio e a Prainha sobressaíram também como espaços gratuitos que restam à população que não pode pagar pelo lazer na cidade. Em locais onde há presença do elemento água para se divertir, as opções privadas são maioria, a exemplo de balneários, pesca e pague, ou Parque Nacional do Iguaçu. No caso da Prainha, apesar da região de Três Lagoas ofertar praças, o local foi colocado por frequentadores - alguns moradores da região -, como única opção para a cidade de Foz do Iguaçu, voltada para o lazer.

\begin{abstract}
"Trago meus filhos, minhas filhas, minhas netas agora. A família toda. É o lazer deles é aqui e não é só meu. É da maioria da população de Foz, não tem outro lugar pra você ir. Não tô dizendo pobre, rico, entendeu? Isso aqui não divide, é pra todo mundo, pra amarelo cor de rosa, preto. O lazer é aqui, entendeu? Se você vai pra uma piscina... Quando eu tinha meus meninos pequenos, eu ia pra piscina, menos de 500 real não podia sair, porque lá você paga pra entrar, paga carro, paga por criança. Tem lugar que não pode levar um refrigerante, uma cerveja. Num clube, numa piscina, num balneário. Aqui não, depois que já tinha os piá, ai chegava domingo, ia pro mercado, comprava minha carninha, cervejinha, meu refrigerante pro meus filhos, a bolacha, os chips deles e vinha pra cá, entendeu? Aqui eles brincavam, jogavam bola, chegava de tardezinha e ia embora. Isso não era só eu, é até hoje todas as famílias, né? ("Flora").
\end{abstract}

O sentimento de pertencimento à Prainha, um local da cidade com apropriações diversas para o lazer, mistura-se a também à indignação com a situação de descaso do local: lixo, desconfiança da água poluída do lago e falta de infraestrutura adequada foram algumas das reclamações. 
"A situação não compensa, olha a situação com tá isso daqui, ruim. Pode vir daqui a um ano pra ver se eles arrumaram, aqui teriam que fazer igual à (Prainha) Santa Helena, fazer quiosquinho bonito, grama bonita, colocar areia, colocar lojas, arrumar e deixar bonito. Mas não faz. Fala que vai fazer e não faz. (...)" ("Ex-pescador")

Esse descaso também está presente em outro espaço da cidade - o Marco das Três Fronteiras. Embora em situação de abandono, o local possui um potencial para o lazer a partir da presença do rio. No entanto, as apropriações para essa finalidade são pontuais. O local é conhecido por ser um dos cartões postais da cidade. Em um mirante, localizado no Marco das Três Fronteiras, é possível ver o encontro dos rios Iguaçu e Paraná, e os demais marcos, representados por obeliscos, em Ciudad del Este (Paraguai) e Puerto Iguazú (Argentina). Portanto, representa o encontro das três nações, símbolo da cidade que sobressai aos olhos, no caso brasileiro, sobretudo de turistas. O olhar para "turista ver" mais uma vez aparece na entrevista com moradores, em relação ao sentimento de pertencimento ao local.

\begin{abstract}
"Até o turista, ele vem mesmo porque ouve falar do Marco das Três Fronteiras e acha que é grande coisa. Eles vêm e não tem... chega aqui e vê que na verdade não é nada. E o preço do artesanato é caríssimo, pra morador principalmente. Porque turista tá viajando tem bastante dinheiro mas pro morador (...)Pras crianças não tem nada. Elas chegaram aqui e falaram: 'pensei que era legal, mas a gente vai ficar muito tempo aqui?' Já chegam de cara e não gostam. (...) É investido bem pouco em espaços públicos, lugar que precisa pagar é investido muito pouco, quase que nada que chama atenção. Lugar bom é o que paga ("Moradora").
\end{abstract}

Esse depoimento remete à relação entre o lazer e a cidade, na qual emergem, segundo Rolnik (2000), conceitos antagônicos do uso do solo urbano, do lazer, dos modos de promoção, da qualidade de vida e do modelo de cidade que cada sociedade está construindo e consumindo. Por um lado, temse a ideia do espaço urbano reduzido a um suporte de conexão de pontos, ou seja, um simples local de acesso, para chegar aos locais onde existe prazer - tanto os espaços domésticos como os de consumo cultural ou esportivo. Outro ponto de vista enxerga o lazer mais conectado à cidade, onde há estreitamento de relação entre os cidadãos e, portanto, com funções sociais e pessoais mais identificados com a dimensão pública da cidade.

No Marco das Três Fronteiras, apesar do descaso do espaço, um grupo de escaladores se apropriaram do chamado Espaço das América, estrutura abandonada e depredada, construída para ser um espaço político e cultural ligado à integração dos povos. Esse grupo utiliza as paredes do Espaço, feitas de pedras naturais empilhadas, para a prática da escalada urbana "artificial", com produto natural. Embora essa prática não seja no rio, ela acontece às suas margens, com interação direta com esse ambiente fluvial.

\footnotetext{
"Tem escalador esportivo que quer graus, quer escalar muito e tal. E tem os aventureiros, que gosta de natureza mesmo, tá escalando pra tá na natureza, escalar faz parte desse pacote, né? A escalada sozinha dentro de uma sala não serve. Então o contexto todo é que faz o troço ficar bonito. (...) Isso do azul da água, o verde da vegetação e o vermelho, marrom, o laranja da rocha, isso é o que deixa o troço mágico. A água sozinha não seria tão bonita. Vamos pensar um rio com um barranco de terra, também é feia. Mas o rio com uma margem verde, é maravilhoso, né? Então essa união de tudo é que faz ficar bonito (...). A gente sente que ainda é muito contemplativo ("Escalador").
} 
Outros grupos de esportistas ligados à natureza também marcam presença no lazer nos rios e margens: são os chamados desportistas de esportes de aventura. O rafting, wakeboard, canoagem, e o mais "modista" da atualidade - o stand up paddle (sup). São esportes que, assim como a escalada, exigem equipamentos tecnológicos de custo alto, portanto, estão restritos a grupos específicos, com maior poder aquisitivo. Essas atividades de lazer, em rios como Iguaçu e Paraná, são praticados literalmente na fronteira. Nessa imersão, emergiu, em certa medida, um contraponto entre esses dois rios, no que tange à segurança para as práticas de lazer.

\begin{abstract}
"No rio Iguaçu, que é onde eu vou mais, a fronteira é bem mais próxima também, porque o rio é menor. $O$ pessoal convive tranquilamente ali, o brasileiro, o argentino, tem as embarcações argentinas, as embarcações brasileiras. A marinha da Argentina não incomoda, a marinha brasileira também não incomoda tanto os argentinos. Os argentinos praticam bastante esporte também. Tem bastante gente andando de caiaque, porque eles têm um acesso bom no porto deles, que é bem de frente ao nosso (Porto Meira), eles têm acesso mais tranquilo." ("Aventureiro").

"Não dá pra conversar, você não tem contato com eles (paraguaios). Às vezes eles xingam, às vezes os daqui provocam também. Xinga em guarani, ofende. (...) Pescando, não tem o que fazer, às vezes fica ofendendo o outro lá, falando em espanhol, guarani e eles rebatem e xingam de lá pra cá também. Na Argentina também tem muito isso aí. Só que na Argentina é mais tranquilo, lá não existe violência nenhuma. ("Caiaque").
\end{abstract}

A fala de "Caiaque" sobre a relação com os paraguaios aponta para o contexto que Haesbaert (2011) sublinha quando discute a questão da transterrritorialidade, inserida no universo de distintas identidades híbridas, que nem sempre são positivamente articuladas, sobretudo nas regiões fronteiriças. $\mathrm{O}$ aumento do perigo, citado por muitos, acarretou o distanciamento do morador com o rio, embora sobreviva um grupo "resistente", que persiste divertir-se beira-rio: são os pescadores amadores.

Uma particularidade ao observar pescarias amadoras, para o lazer, é a reunião de pessoas de diversas faixas etárias e um ambiente que supõe, muitas vezes, um silêncio contemplativo. Nos ambientes de pesca havia os solitários, os que compunham dupla, e grupos. Embora majoritariamente do sexo masculino, há uma diversidade de pessoas que evidenciam que essa atividade de lazer atravessa gerações, apesar das tensões fronteiriças.

\begin{abstract}
"Eu lembro que queria ir, mas nem sempre ele (pai) me levava. Às vezes me levava e às vezes não. Eu gostava, olhava ele tirava aqueles peixão. Meu filho também, vai passando de pai pra filho, né? Se eu não frequentasse o rio, meu filho nem se importava. Foi de geração em geração. Às vezes meu filho... tenho um filho que gosta de pescar comigo, com certeza ele vai pescar também quando crescer. Vai gostar porque ela adora pescar. Vai passando de pai pra filho. Pescaria é muito bom, um hobby, distrai. Às vezes tá muito cansado com a rotina do serviço, vai e pesca, né? Você vai na beira do rio, às vezes não precisa nem pegar peixe, só de você tá lá, você olha o rio e tal, a caminhada no meio do mato, aquilo ali já vai descarregando. ("Caiaque").
\end{abstract}

Essa sensação de "descarrego", citada por "Caiaque", vem acompanhada de diversas representações e imaginários presentes nas falas dos depoentes. Eles enfatizaram que, apesar da relação de "costas" dos moradores em relação aos rios urbanos, as suas "mortes" gerariam perdas de significados vitais para a vida humana, como podemos verificar em alguns depoimentos a seguir. 
"O rio pra mim significa tudo. É a natureza, a sobrevivência, o lazer." ("Marinheiro").

"Pra mim significa tudo, porque não existiria vida sem o rio. A própria cidade de Foz do Iguaçu cresceu em volta dos rios. Não só Foz, várias cidades do Brasil. Primeiro como meio de transporte quando toda a região era coberta por florestas, o rio era que transportava as pessoas, sempre foram estradas naturais. Segundo é fonte de alimento, você pode praticar pesca no rio e lazer. ("Pardal").

"O rio é renovável é relaxar... As atividades de água trazem de volta esse lado de criança de brincadeira, de alegria, é diferente, a gente tá ali escalando e tem sua descontração, mas é um esporte focado, sério, mas quando você entra na agua é folia, né? É brincar na água, por isso tem esse lado bem solto da água." ("Escaladora").

"Aqui é tudo, não é só eu, é Foz do Iguaçu inteira. Tomar chimarrão, tereré, uma cervejinha, Aqui você senta e abre as vistas, olha o mundo, a natureza... é só natureza e sossego. ("Flora").

"É praticamente como se fosse uma religião, é um momento, é um local onde consigo meditar, relaxar, fazer uma oração. Principalmente, uma cachoeira é onde me sinto mais conectado com Deus, eu não vou tanto à Igreja, eu não sigo uma religião. Minha religião é mais a natureza, de tá em contato com a natureza, então é uma coisa até meio que sagrada. ("Aventureiro").

"Significa lazer, vida, tristeza às vezes, emoção, mas mais parte positiva." ("Guarani")

Para os depoentes, o significado holístico do rio ao dizer que ele "é tudo" foi o sentido que mais apareceu sobre o ambiente fluvial de Foz do Iguaçu. Depoimentos que apontam para consciência da dependência da água para sobrevivência e saúde - com lazeres permeando esses caminhos. Os rios também foram concebidos como fontes de subsistência e como espaço potencial para o transporte: os caminhos do cotidiano, do trabalho e dos encontros com o "outro", do lado de lá da fronteira. Ou, ainda, como fontes de renovação do corpo e da alma, ambiente da convivência, de um ritmo de contemplação e um sentido de integração entre o homem e a natureza.

Portanto, a premência de pensar o ambiente construído e o ambiente fluvial, em Foz do Iguaçu, passa pela compreensão de sentidos e significados do ambiente fluvial e do contexto de identidades híbridas. Isso dentro de problemáticas que trazem "tristezas", como apontou o "Guarani", como também potencialidades - a "emoção e parte mais positiva", como ainda aponta esse depoente. Essas possibilidades dos rios, carregadas de representações vitais, também apontam para uma visão sobre as águas, dentro do contexto de direitos, no contexto da cidade e do meio ambiente. 
Quadro 1 - Principais aspectos identificados na relação rio x lazer

\begin{tabular}{|l|l|}
\hline Práticas de lazer & $\begin{array}{l}\text { Principal atividade: pesca esportiva. } \\
\text { Outras: esportes de aventura como rafting, wakeboard, canoagem, stand up paddle } \\
\text { nas margens, escalada. }\end{array}$ \\
\hline Transformações & $\begin{array}{l}\text { O rio identificado, antigamente, como um dos principais locais de lazer da cidade. } \\
\text { Mudança desse cenário a partir das seguintes transformações: } \\
\text { - Perda das prainhas (areiões); } \\
\text { - Migração do lazer para espaços privados; } \\
\text { - Priorização da via terrestre em detrimento do fluvial; } \\
\text { - Urbanização e novas dinâmicas urbanas (conflitos de moradia, problemática de } \\
\text { Saneamento, poluição dos rios, construção de Itaipu, intensificação do comércio } \\
\text { turismo, tráfico na fronteira, violência, sentimento de medo nos espaços fluviais). }\end{array}$ \\
\hline Contradições & $\begin{array}{l}\text { - Olhar de "costas" para a abundância dos ambientes fluviais; } \\
\text { - O turista é privilegiado em detrimento de perspectiva mais próxima do rio } \\
\text { com o morador; } \\
\text { - Discrepância com maior apropriação dos espaços públicos pelo poder privado, e } \\
\text { descaso com os espaços públicos para o lazer; } \\
\text { - Fechamento de portos legais e surgimento de portos ilegais na fronteira. }\end{array}$ \\
\hline $\begin{array}{l}\text { Significados } \\
\text { do rio }\end{array}$ & $\begin{array}{l}\text { - Localístico (saúde, sobrevivência, lazer..); } \\
\text { - Local de lembranças - tristezas e alegrias. }\end{array}$ \\
\hline Potencialidades & $\begin{array}{l}\text { - Rios como espaços que marcam a identidade da cidade e o sentimento de d perte } \\
\text { cimento; } \\
\text { - Lazer nos rios forjam consciência ecológica; } \\
\text { identidades e outros valores culturais, além de ambientes com potencial } \\
\text { integracionista. }\end{array}$ \\
\hline
\end{tabular}

Gorski (2010) verifica, em projetos de recuperação de rios nas cidades, a importância do lazer inserido nesse processo, seja por meio de ciclovias, acesso para pedestres, sistema de parques na orla, parques lineares, áreas que podem receber equipamentos para fins culturais, espaços de convivência ou, ainda, pela possibilidade de práticas esportivas nas águas. Essas ideias estão conectadas com ações de envolvimento da comunidade e acompanhadas de intervenções para despoluição e revitalização das águas, suas margens e seu ecossistema envolto. A pesquisadora chama atenção para as múltiplas potencialidades e funções dos rios:

Rios, riachos, cursos d'água e córregos, no imaginário coletivo, figuram predominantemente associados aos mananciais, porém apresentam propriedades outras, como demarcadores de território, produtores de alimentos, corredores de circulação de pessoas e de produtos comerciais e industriais, corredores de fauna e flora, geradores de energia, espaços livres públicos de convívio e de lazer, marcos referenciais de caráter turístico e elementos determinantes de feições geomorfológicas. (Gorski, 2010, p.31)

No vínculo cidade-natureza, o rio, os riachos, os córregos, as nascentes, os cursos d'água urbanos apresentam-se como elo privilegiado nas apropriações para o lazer. Nesse sentido, Gandara (2008) entende o rio como categoria de análise que representa um sistema indicador da situação espacial, concebido com base nas relações entre natureza e sociedade.

Eles são construtores de "mundos sociais" e aglutinam em torno de si uma boa 
quantidade de representações como "lugar de significação" que são. Servem de baliza ou marco quase míticos para estratégias sócio-culturais. Eles significam muito mais do que acidentes geográficos traçados nos mapas. Os rios não são simples suporte físico. É paisagem, lugar onde as pessoas se abrem aos mistérios da natureza, ao patrimônio simbólico, possibilitando a interpretação como terreno da criação cultural, passagem de forças e encontro dos indivíduos (Gandara, 2008, p.1819).

Nesse sentido, pensar em encontros dos indivíduos e integração na região da Tríplice Fronteira passa por decisões econômicas, políticas e vão além: é a partir do encontro sociocultural com o "estranho" que entrelaça-se e potencializa-se o reconhecimento do outro e o respeito a outras identidades e valores culturais.

\section{CONSIDERAÇÕES FINAIS}

Esta pesquisa teve como objetivo identificar e discutir algumas das apropriações e vivências do lazer em Foz do Iguaçu, em rios urbanos. Os conhecimentos sistematizados ao longo da pesquisa apontam para práticas de lazer pontuais, que foram tornando-se escassas a partir de mudanças urbanísticas e no meio natural da cidade. Essa trajetória de transformações não pode estar desvinculada de contextos imbricados: histórico, sociopolítico, ambiental e cultural. Esses universos integram um conjunto de referências, forças e embates sociais, que influenciaram - e ainda continuam refletindo - em um devir entre os ambientes construído e natural, estes tensionados e transversalmente tangenciados pelo lazer.

Ao considerar o residente em suas relações com os rios urbanos, a relação do pescador e o rio é o que perdura e resiste mais visivelmente no contexto investigado. O lazer, nos rios e suas margens, sobrevive também por meio de práticas esportivas - interativas e contemplativas com as águas - ou, ainda, realizadas a partir de reapropriação de equipamentos beira-rio, como foi o caso da prática de escalada. Essas práticas de lazer podem ser pensadas como um catalisador - ou potencializador - para o encontro e a comunicação entre as pessoas e a diversidade. Essas práticas e vivências de lazer democráticas devem, portanto, ser pensadas a partir do valor de uso (do encontro), em detrimento do de troca (da mercadoria).

Os rios e as regiões "verdes" são símbolos da separação e união entre os países (Brasil, Argentina e Paraguai), onde vivências de lazer ainda são possíveis e visíveis. $O$ olhar e a vivência interativos e contemplativos nos rios sobrevivem mediados por medo, insegurança e controvérsias, que passam pelo contexto de injustiças sociais e ambientais.

As contradições percebidas partem do olhar voltado em função do turista, em detrimento de uma perspectiva mais próxima e atenta aos moradores de Foz do Iguaçu e as reivindicações deste grupo; ou, ainda, de uma força maior dos espaços privados sobre os públicos. Além disso, percebese uma visão que, ainda, harmoniza relação entre natureza e capital. A reivindicação por espaços democráticos, revitalização e conservação ambiental dos rios passa por uma veia crítica de que embates de forças, de classes, racionalidades e busca por legitimações constroem hegemonias e invisibilidades.

O lazer contribui com esse debate ao abrir frestas às perspectivas de criar um vínculo mais integracionista entre essa população de fronteira; entre a sociedade e o meio ambiente; entre o meio ambiente e o urbano; entre os moradores da região e os espaços representativos de sua cida- 
de. A consciência e o questionamento sobre de que forma o rio é significado, representado e apropriado por meio de diversas práticas sociais, nelas incluídas o lazer, portanto, urgem.

Invisibilizar esse vínculo em Foz do Iguaçu, esse sentimento de pertencimento a uma cidade, vindo de sua relação com seus espaços e sua natureza, é destruir uma história, ou melhor, muitas histórias de vínculos afetivos entre seus moradores. É fechar os olhos para uma urgência que necessita "insurgências" de luta pelas águas.

Dessa forma, caminha-se ao campo do direito público à água: um debate que passa por instâncias da sobrevivência humana, saúde, moradia e do lazer. Flui e abraça, ainda, outros debates sobre o direito à cidade e aos espaços democráticos, para o encontro com outras realidades, além de práticas esportivas, culturais, espirituais e contemplativas.

\section{REFERÊNCIAS}

Béliveau, V. G. (2011). Representações da integração e seus obstáculos: A fronteira do ponto de vista da política. In: L. Macagno, S. Montenegro, V. Béliveau (org.). In A Tríplice Fronteira: espaços nacionais e dinâmicas locais. Curitiba: Editora UFPR.

Bogdan, R. \& Biklen, S. (1994). Investigação qualitativa em educação: uma introdução à teoria e aos métodos. Porto, Portugal: Porto Editora.

Catta, L. E. (2009). A face da desordem - Pobreza e estratégias de sobrevivência em uma cidade de fronteira (Foz do Iguaçu/1964-1992). São Paulo: Editora Blucher Acadêmico.

Gandara, G. S. (2008). Rio Parnaíba... cidades-beira. Tese de doutorado, Universidade de Brasília, Brasília, DF, Brasil.

Germani, G. I. (2003). Expropriados. Terra e água: o conflito de Itaipu. (2ª ed). Salvador: EDUFBA, ULBRA.

Gibbs, G. (2009). Análise de dados qualitativos. Porto Alegre: Artmed.

Gomes, C. (2014) Lazer: necessidade humana e dimensão da Cultura. In Revista Brasileira de Estudos do Lazer (RBEL), v.1, n.1, 3-19. Recuperado em 01 de junho, 2015, de https://seer.lcc.ufmg.br/index.php/rbel/article/view/327/227.

Gomes, P. C. (2012). A condição urbana - ensaios da geopolítica da cidade. (4a ed). Rio de Janeiro: Editora. Bertrand.

González, E. (2005). Memórias que narram a cidade: Experiências sociais na constituição urbana de Foz do Iguaçu. Dissertação de mestrado, Pontifícia Universidade Católica de São Paulo, São Paulo, SP, Brasil.

Gorski, Maria Cecília Barbieri. Rios e cidades: ruptura e reconciliação. São Paulo: Editora Senac, 2010.

Haesbaert, R. (2011). Multi/transterritorialidade e o "contornamento": do trânsito por múltiplos territórios ao contorno dos limites fronteiriços. In N. C. Fraga (org.). Territórios e fronteiras - (re)arranjos e perspectivas. Florianópolis: Insular. 
Oliveira, N. (2012). Foz do Iguaçu Intercultural - Cotidiano e narrativas da alteridade. Foz do Iguaçu: Editora Epígrafe.

Organização dos Estados Americanos (2009). Aquífero Guarani: programa estratégico de ação - Edição bilíngue - Brasil; Argentina; Paraguai; Uruguai. Recuperado em 05 de outubro, 2014, de http://www2.ana.gov.br/Paginas/projetos/GEFAquiferoGuarani.aspx.

Rabossi, F. (2011). Como pensamos a Tríplice Fronteira? In L. Macagno, S. Montenegro, V. Béliveau (org.). A Tríplice Fronteira: espaços nacionais e dinâmicas locais. Curitiba: Editora UFPR.

Rolnik, R. (2000). O lazer humaniza o espaço urbano. In Lazer numa sociedade globalizada: Leisure in a globalized society. São Paulo: Sesc/WLRA.

Souza, A. D. de (2009). Formação econômica e social de Foz do Iguaçu: um estudo sobre as memórias constitutivas da cidade (1970-2008). Tese de doutorado, Universidade de São Paulo, São Paulo, SP, Brasil.

Thaumaturgo, L. R. Y (2012). A expansão urbana e o crescimento populacional em áreas do entorno de grandes reservatórios: o caso de Foz do Iguaçu. Tese de doutorado, Universidade Estadual Paulista, Guaratinguetá, SP, Brasil.

Vainer, C. (2000). Pátria, Empresa e Mercadoria - Notas sobre a estratégia discursiva do Planejamento Estratégico Urbano. In A cidade do pensamento único: desmanchando consensos. O. Arantes, C. Vainer, E. Maricato (org). Petrópolis: Vozes.

Artigo recebido em: 25/05/2015. Artigo aprovado em: 27/07/2016.

\section{Sandra Akemi Narita}

Mestra em Estudos do Lazer na Universidade Federal de Minas Gerais (UFMG). Graduada em Comunicação pela Universidade Federal da Bahia. Jornalista da Universidade Federal da Integração Latino-Americana (UNILA).E-mail: sandranarita@hotmail.com.

\section{Christianne Luce Gomes}

Doutora em Educação pela UFMG, com pós-doutorado em Ciências Políticas e Sociais pela Universidade Nacional de Cuyo, Mendoza/Argentina. Docente do Programa de Pós-graduação Interdisciplinar em Estudos do Lazer da UFMG E-mail: chris@ufmg.br 